\title{
Retinoic acid-mediated down-regulation of ENO1/MBP-1 gene products caused decreased invasiveness of the follicular thyroid carcinoma cell lines
}

\author{
Bogusz Trojanowicz ${ }^{1,2}$, Anja Winkler ${ }^{1}$, Kathrin Hammje ${ }^{1}$, Zhouxun Chen ${ }^{1,2}$, Carsten Sekulla ${ }^{1}$, \\ Dagobert Glanz ${ }^{3}$, Cornelia Schmutzler ${ }^{4}$, Birgit Mentrup ${ }^{5}$, Sabine Hombach-Klonisch ${ }^{6}$, \\ Thomas Klonisch $^{6}$, Rainer Finke ${ }^{2}$, Josef Köhrle ${ }^{4}$, Henning Dralle ${ }^{1}$ and Cuong Hoang-Vu ${ }^{1}$ \\ ${ }^{1}$ AG Experimentelle \& Chirurgische Onkologie, Universitätsklinik und Poliklinik für Allgemein-, Viszeral- und Gefäßchirurgie, Martin-Luther Universität, Magdeburger Strasse 18, 06097 \\ Halle/S., Germany \\ ${ }^{2}$ Universitätsklinik und Poliklinik für Kinderchirurgie, Martin-Luther Universität, Halle, Germany \\ ${ }^{3}$ Institut für Physiologische Chemie, Martin-Luther Universität, Halle, Germany \\ ${ }^{4}$ Institut für Experimentelle Endokrinologie, Charité, Universitätsmedizin Berlin, Berlin, Germany \\ ${ }^{5}$ Orthopedic Center for Musculoskeletal Research, University of Wuerzburg, Wuerzburg, Germany \\ ${ }^{6}$ Department of Human Anatomy \& Cell Science, University of Manitoba, Winnipeg, Manitoba, Canada \\ (Correspondence should be addressed to C Hoang-Vu; Email: hoang-vu@ medizin.uni-halle.de)
}

\begin{abstract}
Retinoic acid (RA) acts as an anti-proliferative and redifferentiation agent in the therapy of thyroid carcinoma. Our previous studies demonstrated that pretreatment of follicular thyroid carcinoma cell lines FTC-133 and FTC-238 resulted in decreased in vitro proliferation rates and reduced tumor cell growth of xenotransplants. In addition to the previous results, we found that RA led to decreased vitality and invasiveness of FTC-133 and FTC-238 cells as they reacted with reduction of intracellular ATP levels and number of migrated cells respectively. However, the molecular mechanisms by which RA mediates these effects are not well understood. Two-dimensional (2D) screening of the proteins related to ATP metabolism and western blot analysis revealed $\alpha$-enolase (ENO1) to be down-regulated in FTC-133 and FTC-238 cells after RA treatment. 2D gel detection and mass spectrometric analysis revealed that ENO1 existed as three separate protein spots of distinct pls (ENO1-A1-A3). Comparative 2D difference gel electrophoresis analysis of fluorescently labeled protein samples of RA-treated and untreated FTC-133 demonstrated a selective down-regulation of ENO1-A1 which we identified as a phosphoprotein. RA caused the dephosphorylation of ENO1-A1. Both, RA-mediated and specific knock-down of ENO1/MBP-1 resulted in the reduction of MYC oncoprotein, and simultaneously decreased proliferation rates of FTC-133 and FTC-238 cell lines. In summary, the RA-mediated down-regulation of the ENO1 gene products and MYC oncoprotein provides a novel molecular mechanism facilitating the anti-proliferative effect of RA in human thyroid carcinoma cells and suggests new pathways for supportive RA therapies.
\end{abstract}

Journal of Molecular Endocrinology (2009) 42, 249-260

\section{Introduction}

The vitamin A (retinol)-derived retinoic acids (RA) are important regulators of a diverse spectrum of physiological processes, including cell proliferation, differentiation, morphogenesis, angiogenesis, and apoptosis (Maden 2000, Biesalski \& Nohr 2003, Buletic et al. 2006). The pleiotropic effects of retinoids are mediated by a nuclear heterodimeric pair of retinoid receptors (RAR/RXR). Retinoid-activated RAR/RXR heterodimers mediate the transcription of specific gene networks, by binding to specific DNA response elements and recruiting cofactor complexes which cause the local chromatin structure to alter and engage the basal transcription machinery. RARs and RXRs also integrate a variety of signaling pathways through phosphorylation events which cooperate with the ligand for the control of retinoid-target genes transcription. Signaling cascades involve FOS, MAPK, PI3 kinase, AKT, cyclins, cyclin-dependent kinases and their inhibitors, Bcl proteins and caspases, all of which are involved in the control of cell growth, differentiation, and apoptosis (Niles 2000). RA was successfully used for the treatment of hematological as well as therapy and chemoprevention of solid cancers (Hansen et al. 2000, Lengfelder et al. 2005) including thyroid carcinomas (Simon et al. 2002). Cell culture experiments in thyroid carcinoma cell lines showed that RA treatment affects thyroid-specific functions, cell-cell or cell-matrix 
interaction, differentiation markers, growth, and tumorigenicity (Schmutzler \& Kohrle 2000). RA has an antiproliferative effect on the follicular thyroid carcinoma cell lines FTC-133 and FTC-238. Furthermore, pretreatment of these cell lines with RA results in decreased in vitro proliferation rates and reduced tumor cell growth of xenotransplants (Schmutzler et al. 2004).

Enolases are glycolytic enzymes responsible for the ATP-generating conversion of 2-phosphoglycerate to phosphoenolpyruvate. In vertebrates, there are three different tissue-specific isoenzymes: the $\alpha$-enolase, ENO1, is expressed in a wide variety of tissues, whereas $\beta$-enolase is localized mainly in muscle and $\gamma$-enolase is specific for neuronal tissues (Merkulova et al. 2000). The ENO1 transcript encodes two structurally and functionally distinct proteins, a $48 \mathrm{kDa}$ ENO1 enzyme and the $37 \mathrm{kDa} M Y C$ promotor-binding protein MBP-1. Enzymatic activity resides within the N-terminal portion, which is unique to ENO1 and absent in MBP-1 (Feo et al. 2000, Subramanian \& Miller 2000, Pancholi 2001). Increased ENO1 gene activity and protein production have been detected in several carcinomas, including neuroendocrine tumors, neuroblastoma, lung cancer, hepatocellular carcinoma, and breast cancer cells, and suggest an involvement of ENO1 in tumor progression (Royds et al. 1982, Kato et al. 1983, Kaiser et al. 1989, Ledermann 1994, Niklinski \& Furman 1995, Redlitz et al. 1995, Ebert et al. 1996, Joseph et al. 1996, Chang et al. 2003, 2006, Takashima et al. 2005, Zhang et al. 2005, Huang et al. 2006, Yoon et al. 2006). The up-regulation of ENO1, glucose phosphate isomerase, and glyceraldehyde-3-phosphate dehydrogenase (GAPDH) in thyroid oncocytoma tumors identifies ENO1 as a member of a metabolic signature in thyroid tumors (Baris et al. 2004). The increased presence of ENO1 could result in accelerated ATP production and, thus, ENO1 may act as a metabolic tumor promoter conferring a selective growth advantage onto ENO1 overexpressing tumor cells.

Here we show that RA treatment of the human follicular thyroid carcinoma cell lines FTC-133 and FTC-238 causes the down-regulation of ENO1 and MBP-1 and this correlated with both reduction of cell invasiveness and the down-regulation of MYC oncoprotein. Moreover, we provide first evidence by two-dimensional (2D) gel electrophoresis and mass spectrometric analysis of an RA-induced alteration in ENO1 phosphorylation.

\section{Materials and methods}

\section{Cell culture, RA stimulation, and RNAi}

The human follicular thyroid carcinoma cell lines FTC133 and FTC-238, and undifferentiated thyroid carcinoma cell lines Hth74, C-643, 8505C, SW1736 were cultured in DMEM/F12 medium, supplemented with $1.125 \mathrm{~g} / 1$ sodium carbonate and $10 \%$ FCS. For treatment with RA, $8 \times 10^{5}$ cells were plated in $75 \mathrm{~cm}^{2}$ flasks and cultured to $80 \%$ confluency. The day before treatment, growth medium was replaced with serumfree medium. After $24 \mathrm{~h}$, the cells were treated with $1 \mu \mathrm{M}$ RA dissolved in ethanol for 24,48 , and $72 \mathrm{~h}$ in a standard humidified incubator $\left(37^{\circ} \mathrm{C}, 5 \% \mathrm{CO}_{2}\right)$. Untreated controls cells were cultured in medium with the same concentration of ethanol but without RA. Medium was replaced daily. For RNAi analysis, $200 \mathrm{nM}$ siRNA targeting ENO1 was applied (5'-AAC-CAG-CTCCTC-AGA-ATT-GAA-3', Qiagen). Non-silencing, randomized sequence 5'-AAT-TCT-CCG-AAC-GTGTCA-CGT-3' not matching any known human gene served as a control. Transfection was done in the presence of OptiMem (Invitrogen) medium and analyses were performed after $72 \mathrm{~h}$. All experiments were repeated at least three times.

\section{Motility assay}

Motility of FTC-133 and FTC-238 cells pretreated with RA was evaluated in 24-well Transwell chambers (Costar, Bodenheim, Germany). The upper and lower culture compartments were separated by polycarbonate filters with $8 \mu \mathrm{m}$ pore size. To investigate the effect of RA on the motility of differentiated thyroid carcinoma cells, FTC-133 or FTC-238 were pretreated with $1 \mu \mathrm{M}$ RA (dissolved in ethanol) for $72 \mathrm{~h}$ and then plated at $1 \times$ $10^{4}$ cells/well in DMEM/F12 medium without FCS. Control cells were pretreated with medium containing the same concentration of ethanol but without RA. The cells migrated from upper to lower compartment for $24 \mathrm{~h}$ in a $5 \% \mathrm{CO}_{2}$ atmosphere at $37^{\circ} \mathrm{C}$. After a $24-\mathrm{h}$ motility period, cells remaining on top of the filter were wiped off with cotton swabs and those cells that had traversed the membrane pores to the lower surface of the membrane were washed with chilled PBS, incubated for $5 \mathrm{~min}$ in 1:1 PBS/methanol (Merck) and $15 \mathrm{~min}$ in methanol before staining with $0 \cdot 1 \%$ toluidine blue (Merck) in $2.5 \%$ sodium carbonate (Roth, Karlsruhe, Germany). Migrated cells were counted by light microscopy (Zeiss, Jena, Germany) in four separate high-power fields per filter.

\section{Western blot}

About $20 \mu \mathrm{g}$ total protein lysate from RA-stimulated and untreated FTC-133 and FTC-238 cells, and $200 \mu \mathrm{g}$ (for 2D western blot) of total protein from wild-type FTC133, were separated on $10 \%$ polyacrylamide gels and blotted on a PVDF membrane (Amersham Biosciences). Blocking was performed in $5 \%$ non-fat milk 
powder $/ 1 \times$ TBST (Tris buffered saline $/ 0.05 \%$ Tween20). After thrice washing with $1 \times$ TBST, membranes were incubated overnight with enolase C-19 polyclonal goat antiserum (1:10 000), MYC (1:1000) (both Santa Cruz Biotechnology, Santa Cruz, CA, USA) and $\beta$-actin $(1: 10000$, Sigma) in $1 \times$ TBST. Secondary anti-goat $(1: 50000)$ and anti-mouse (1:20 000) antibodies were used (both Santa Cruz Biotechnology). Immunoreactive bands for ENO1, MBP-1, MYC, and $\beta$-actin were visualized using the ECL Detection Kit (Amersham Biosciences) and Kodak Image System 440cf (Eastman Kodak, Rochester, NY, USA).

\section{Protein extraction and purification for 2D gel electrophoresis}

FTC-133 cells were washed twice with PBS prior to the protein extraction. Proteins were extracted using two different lysis buffers, a) a standard 2D lysis buffer was used for silver staining (8 M Urea, 4\% CHAPS, $1 \%$ dithiothreitol (DTT), 0.8\% Pharmalyte) and b) a 2D extraction buffer for use with fluorescent-labeled dyes (7 M Urea, 2 M Thiourea, 4\% CHAPS, 2\% Pharmalyte, $2 \%$ DTT). Cells were incubated with lysis buffers for $30 \mathrm{~min}$ at room temperature (RT) and further purified with the trichloroacetic acid (TCA)-based 2D Clean Up Kit (Amersham Biosciences). Purified proteins were dissolved in rehydration solution for use in silverstained gels (8 M Urea, 2\% CHAPS, $0.5 \%$ Pharmalyte, $40 \mathrm{mM}$ DTT) or fluorescent-labeled gels (8 M Urea, $1 \%$ CHAPS, $0.4 \%$ DTT, $0.4 \%$ Pharmalyte) and stored at $-80^{\circ} \mathrm{C}$ until use.

\section{Two-dimensional gel electrophoresis}

Isoelectric focusing (IEF, first dimension) was carried out on an IPGphor (Amersham Biosciences). Total protein (30 or $150 \mu \mathrm{g}$ ) was loaded onto nonlinear, $18 \mathrm{~cm}(\mathrm{pH} 3-10)$ immobilized $\mathrm{pH}$ gradient (IPG) strips and rehydrated under low voltage conditions $(30 \mathrm{~V})$ for $12 \mathrm{~h}$. For 2D fluorescence difference gel electrophoresis (DIGE), $30 \mu \mathrm{g}$ total protein from RA-stimulated and untreated FTC-133 control were labeled with dyes Cy2 (blue, control) and Cy3 (green, RA-treated; Amersham Biosciences) respectively. Labeling reactions were incubated for $30 \mathrm{~min}$ on ice in the dark and stopped for $10 \mathrm{~min}$ with $10 \mathrm{mM}$ lysine. Labeled proteins were combined at a 1:1 ratio, dissolved in rehydration solution, and IEF was performed at $8000 \mathrm{~V}$ for $9 \mathrm{~h}$. IPG strips were equilibrated first in $10 \mathrm{ml}$ equilibration solution (6 M urea, $2 \%$ SDS, $50 \mathrm{mM}$ Tris-HCl (pH 8.8), 30\% glycerol) with $100 \mathrm{mg}$ DTT (Roth) for $15 \mathrm{~min}$ and in $10 \mathrm{ml}$ equilibration solution with $250 \mathrm{mg}$ iodoacetamide (IAA, Sigma) for another $15 \mathrm{~min}$. Then IPG strips were arrested on a $12.5 \%$ polyacrylamide gel (37.5:1 Rothiphorese Gel 30, $10 \%$ SDS, 1.5 M Tris-HCl (pH 8.8), 10\% APS, TEMED) using $0.5 \%$ agarose.

Second dimensional electrophoresis was performed in an Ettan Dalt Unit (Amersham Biosciences) using SDS electrophoresis buffer (Tris-base $25 \mathrm{mM}$, glycine $192 \mathrm{mM}$, SDS $0 \cdot 1 \%$ ) at $2.5 \mathrm{~W} / \mathrm{gel}$ for $30 \mathrm{~min}$ and at $5 \mathrm{~W} /$ gel for the next 5-6 h. For silver staining, gels were fixed for $1 \mathrm{~h}$ in $40 \%$ ethanol, $10 \%$ acetic acid, washed $3 \times 20 \mathrm{~min}$ in $30 \%$ ethanol, sensitized in $0.02 \%$ sodium thiosulfate, washed $3 \times 20 \mathrm{~s}$ in distilled water $\left(\mathrm{H}_{2} \mathrm{Odest}\right)$. Staining was performed for $20 \mathrm{~min}$ with $0.25 \%$ silver nitrate, $0 \cdot 00925 \%$ formaldehyde. Gels were washed $3 \times 20 \mathrm{~s}$ in $\mathrm{H}_{2}$ Odest, developed in $3 \%$ sodium carbonate, $0.0185 \%$ formaldehyde, washed $20 \mathrm{~s}$ in $\mathrm{H}_{2}$ Odest, and the silver staining reaction was stopped after exactly $10 \mathrm{~min}$ in $5 \%$ acetic acid and $3 \times 10 \mathrm{~s}$ washing in $\mathrm{H}_{2} \mathrm{Odest}$. For semi-quantitative protein spot evaluation, silver stained gels were scanned using a visual light scanner Hewlet Packard scanjet 7400C and analyzed with Phoretix 2D software (Nonlinear Dynamics, Newcastle upon Tyne, UK). Fluorescently labeled protein gels were analyzed using the Typhoon scanner and the DeCyder pro software (Amersham Biosciences). Up-regulated proteins isolated from untreated FTC-133 and labeled with Cy2 appeared as blue spots. Up-regulated proteins from RA-treated FTC133 labeled with Cy3 appeared as green spots. White, overlapped protein spots indicate no difference between control and RA-treated cells.

\section{Protein preparation for mass spectrometry}

Spots of interest (molecular range between 30 and $60 \mathrm{kDa})$ were excised from gels, chopped into cubes $\left(\sim 1 \mathrm{~mm}^{3}\right)$, and dried in a vacuum concentrator. For MALDI-ToF MS analysis, spots were destained with $100 \mathrm{mM}$ potassium ferricyanide $/ 30 \mathrm{mM}$ sodium thiosulfate, washed with water (HPLC grade, Roth), shrunk with acetonitrile $(\mathrm{ACN})$, and dried in a vacuum concentrator. The dried gel pieces were rehydrated with 30-50 $\mu \mathrm{l}$ cold trypsin solution $(15 \mu \mathrm{g} / \mathrm{ml})$. Digestion was performed for $16-24 \mathrm{~h}$ at $37^{\circ} \mathrm{C}$. Peptides were extracted twice with $50 \mathrm{ACN} / 5 \%$ trifluoroacetic acid (TFA) and dried. For Q-ToF-MS/MS analysis, protein spots were washed with water (HPLC grade, Roth), shrunk with acetonitrile, and dried. Proteins were reduced (100 mM DTT in $100 \mathrm{mM} \mathrm{NH} \mathrm{HCO}_{3}$ ), alkylated (55 mM IAA in $\left.100 \mathrm{mM} \mathrm{NH}_{4} \mathrm{HCO}_{3}\right)$, and digested with $12.5 \mathrm{ng} / \mu \mathrm{l}$ trypsin dissolved in $5 \mathrm{mM} \mathrm{CaCl}_{2} / 50 \mathrm{mM}$ $\mathrm{NH}_{4} \mathrm{HCO}_{3}$. Peptides were extracted with ACN/5\% formic acid and dried in a vacuum concentrator. Desalting was performed with ZipTip (Millipore Corporation, Billerica, MA, USA) containing $\mathrm{C}_{18}$ 
reverse-phase medium. Peptides desalted for MALDIToF MS were dissolved in $50 \% \mathrm{ACN} / 0 \cdot 1 \%$ TFA and for Q-ToF MS/MS in $70 \%$ methanol/1\% formic acid.

\section{Mass spectrometric analysis}

MALDI-ToF MS identification of peptide mixtures was performed on a VoyagerDE Pro mass spectrometer (Applied Biosystems, Forester City, CA, USA). Dissolved peptides (50\% ACN $/ 0 \cdot 1 \%$ TFA) were combined with matrix ( $\alpha$-cyano-4-hydroxy-trans-cinnamic acid) in a 1:1 ratio (vol:vol) and spotted onto the sample plate. Mass spectra were externally calibrated with Sequazyme Protein Digest Standards Kit (Applied Biosystems) containing des-Arg ${ }^{1}$-bradykinin, angiotensin I, Glu ${ }^{1}$ fibrinopeptide-B, neurotensin, $\beta$-galactosidase, and glycogen phosphorylase. Protein identification was performed using Mascot DataBase, where peptide mass tolerance was set to $100 \mathrm{ppm}$. One possible missed cleavage for trypsin digestion was allowed. Spectra were reconstructed with DataExplorer and analyzed with Mascot data bank.

MS/MS protein analyses were performed using the QSTAR Q-ToF mass spectrometer (Applied Biosystems) equipped with a nanospray source. External mass calibration in ToF mode was performed using synthetic sex determining octapeptide (Bachem AG, Bubendorf, Switzerland) combined with cesium iodide (Sigma) dissolved in a mixture of water/methanol/formic acid $(49 \cdot 5 / 49 \cdot 5 / 1)$. For mass calibration in MS/MS mode, we used Glu-fibrinopeptide-B (Sigma) diluted in $30 \%$ methanol $/ 1 \%$ formic acid. Protein identification, sequencing, and modification mapping were performed using BioAnalyst software and PepSea server (Applied Biosystems). Mass tolerance was set to 50 and $100 \mathrm{ppm}$ and no missed cleavages for trypsin were allowed.

\section{MTT and ATP assays}

In 96-well plates, $5 \times 10^{3}$ FTC-133 and FTC-238 cells were seeded and cultured with DMEM-F12 medium without FCS. After $24 \mathrm{~h}$, RA was added and cells were incubated for additional 24, 48, and $72 \mathrm{~h}$. For MTT assay, cells were stained with MTT (3-[4, 5-dimethylthiazol-2-yl]-2,5-diphenyltetrazolium bromide) for $4 \mathrm{~h}$ at $37^{\circ} \mathrm{C}$. Colorimetric measurements were done with a Tecan Elisa Reader (Tecan, Grödig, Austria). For ATP assays, substrate (100 $\mu \mathrm{l})$ was added to each well (CellTiter-Glo Luminescent, Promega) and incubated with the cells on a shaker and on the bench top for $2 \mathrm{~min}$ and $10 \mathrm{~min}$ respectively. Luminescence was measured with a Sirius luminometer (Berthold Detection Systems, Pforzheim, Germany). All experiments were done in triplicates.

\section{Apoptosis assay}

Control and RA-treated FTC-133 and FTC-238 cells were incubated with Annexin-V-Fluos staining kit (Roche). Annexin V is a $\mathrm{Ca}^{2+}$-dependent phospholipid-binding protein with high affinity for phosphatidylserine (PS). Since both apoptotic and necrotic cells expose PS, simultaneous staining with propidium iodide was employed in order to discriminate between red necrotic and green labeled apoptotic cells. Evaluations were performed using Axioplan 2 fluorescent microscope and Axiovision software (Zeiss). Additionally expression of annexin $\mathrm{V}$ was evaluated by DIGE and mass spectrometric analysis.

\section{Results}

\section{RA-induced decreased proliferation and motility of follicular thyroid carcinoma cell lines, but not apoptosis}

In order to investigate whether different thyroid carcinoma cell lines respond to RA treatment with altered proliferation, follicular thyroid carcinoma cells FTC-133 and FTC-238, and 8505C, C-643, Hth74, SW1736 representing undifferentiated thyroid carcinoma, were subjected to MTT assay. As shown in Fig. 1A, out of six cell lines analyzed, only FTC-133 and FTC-238 responded to RA treatment with significantly reduced proliferation rates. Other cell lines revealed only slightly changed proliferation profiles; however, the differences were not significant. Our further investigations were focused on differentiated thyroid cell lines FTC-133 and FTC-238 only. Previous experiments demonstrated decreased metabolic activity of both cell lines. To further verify whether RA actions are connected with reduced vitality and energy production, we measured intracellular ATP levels in these cell lines. Figure 1B demonstrates ATP assay performed by the evaluation of luminescence after 24, 48, and $72 \mathrm{~h}$ of RA treatment. Similar to MTT assay, also in this case, investigated cell lines responded to RA with significantly decreased vitality, especially visible after $72 \mathrm{~h}$. To examine the effects of RA on invasiveness of FTC-133 and FTC-238, the cells pretreated with RA for $72 \mathrm{~h}$ were subjected to motility assays. As demonstrated in Fig. 2A, migrated control and RA-treated cells were stained and photographed using light microscopy (lower panel). Decreased number of migrated cells is visible on both RA-pretreated filters as compared with controls. Also cell counting revealed significantly reduced motility rates for both cell lines after RA pretreatment (upper panel). In order to examine whether observed RA effects could be due to apoptosis induction, control and RA-treated cells were stained with the apoptosis marker 
A

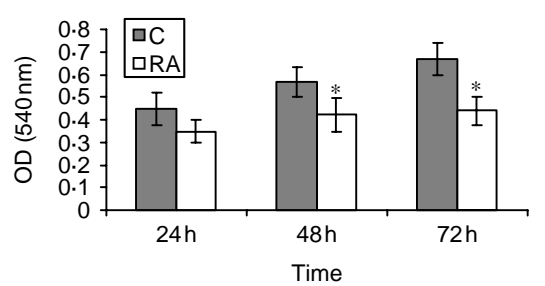

$8505 \mathrm{C}$

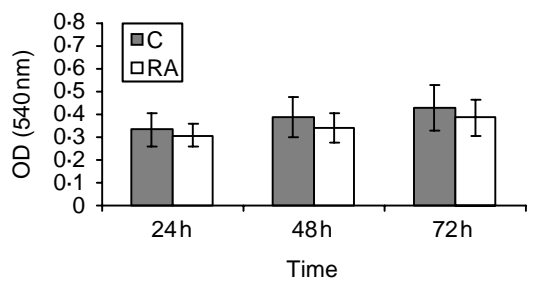

HTh74

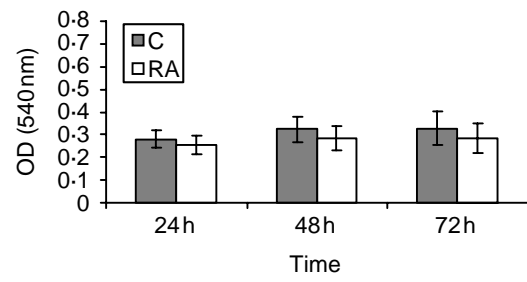

B

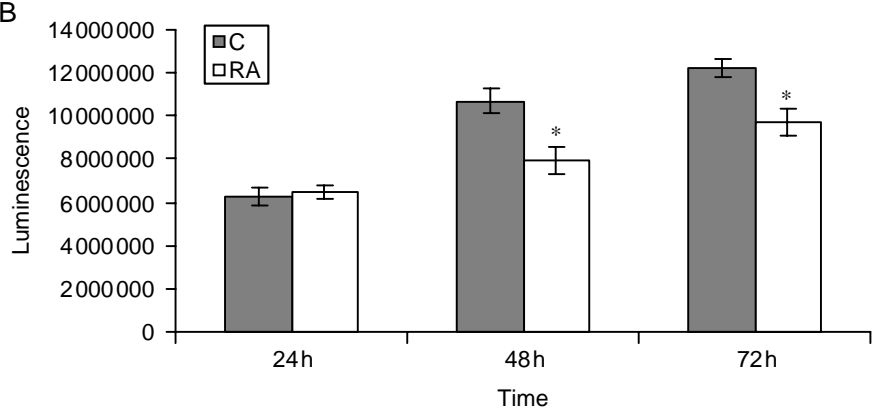

FTC-238

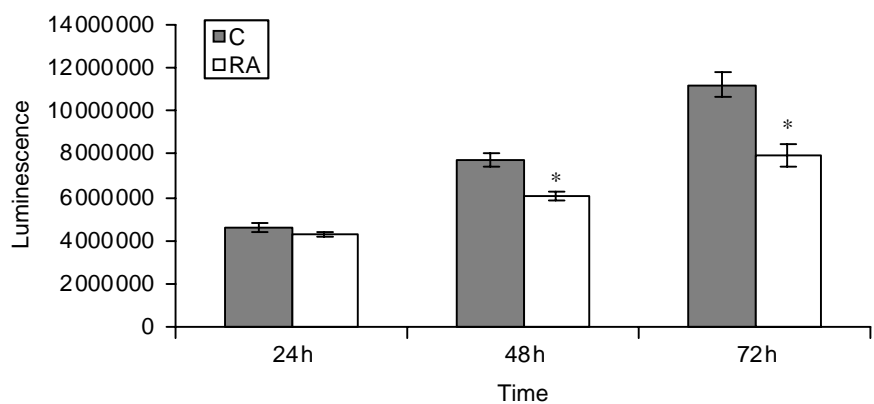

Figure 1 Proliferation and vitality of thyroid carcinoma cell lines upon RA treatment. (A) Differentiated (FTC-133, FTC-238) and undifferentiated (8505C, C-643, HTh74, SW1736) thyroid carcinoma cell lines were subjected to MTT assay. Significant response to RA treatment is visible for FTC-133 and FTC-238 cell lines only. (B) Vitality assay performed on FTC-133 and FTC-238 cells. Both cell lines responded with significantly decreased intracellular ATP levels. 


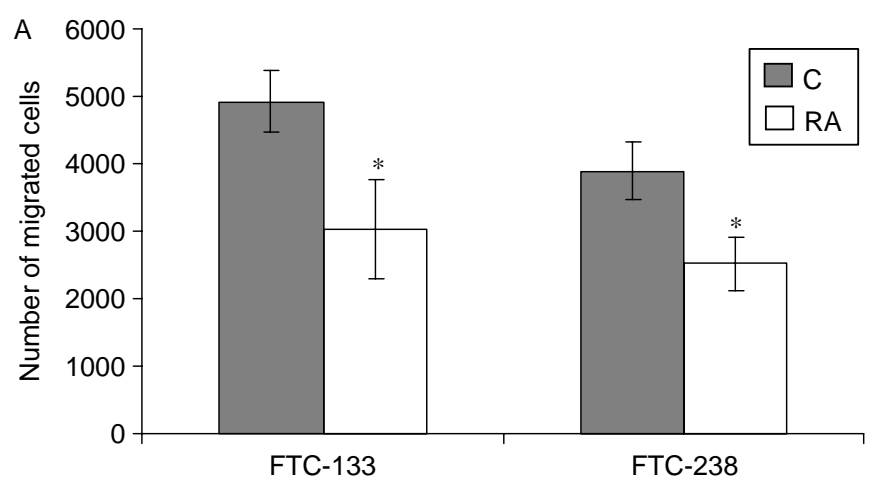

FTC-133

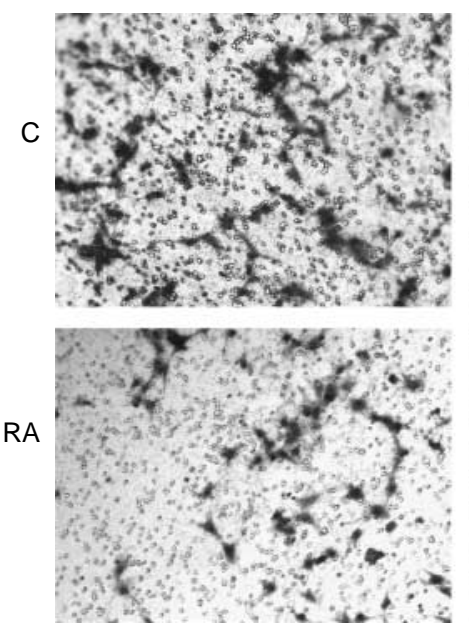

B
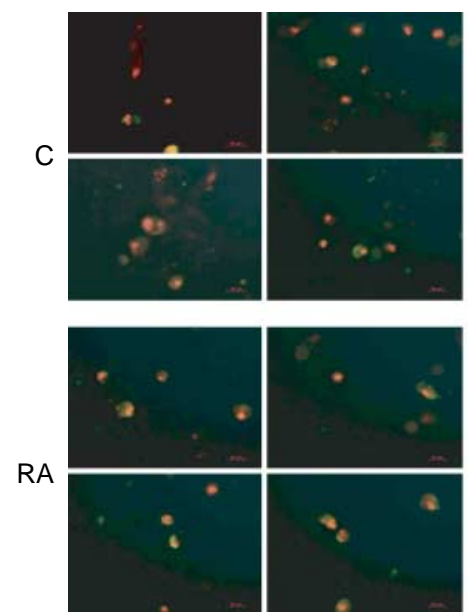

FTC-238
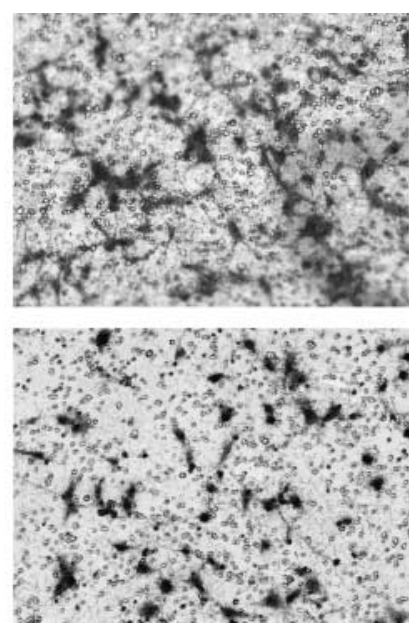

FTC-238
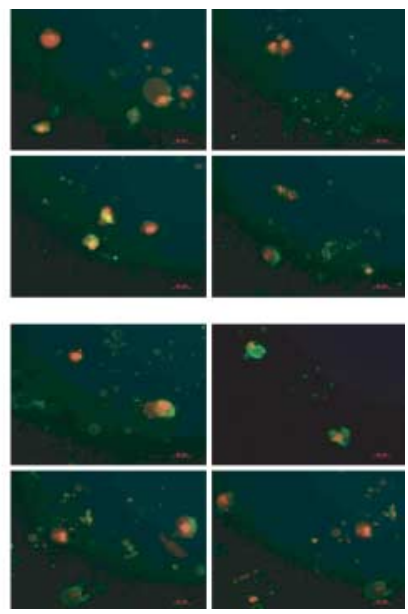

Figure 2 Invasiveness and apoptosis of thyroid carcinoma cell lines upon RA treatment. (A) Control and RA-pretreated FTC-133 and FTC-238 cells were subjected to motility assay. Filters with migrated cells were stained with $0 \cdot 1 \%$ toluidine blue and photographed under light microscope. As demonstrated in lower panel, RA pretreatment led to visible reduction of migrated cells. Cell counting presented in upper panel revealed significantly decreased number of migrated cells upon RA treatment. (B) Apoptosis assay revealed the presence of annexin V (green staining) both in control and RA-treated cells; however, no difference is visible. Red staining with propidium iodide indicate the presence of necrotic cells. 
annexin V (Fig. 2B). However, investigations performed by employing fluorescent microscopy revealed no noticeable differences in annexin $\mathrm{V}$ and propidium iodide staining. Both control and RA-treated cells revealed the presence of apoptotic and necrotic cells. Additionally,

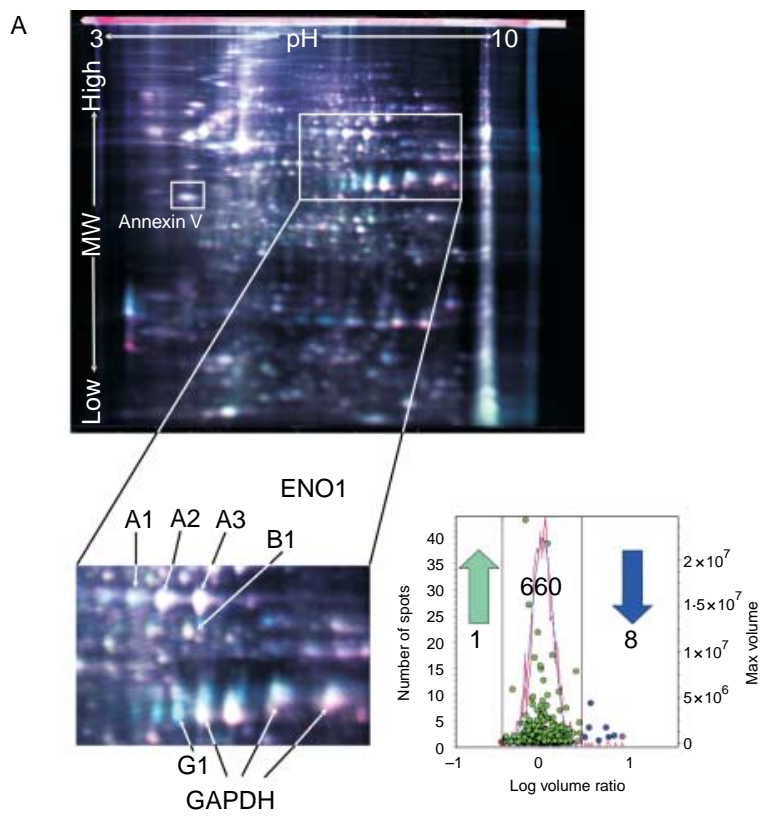

B

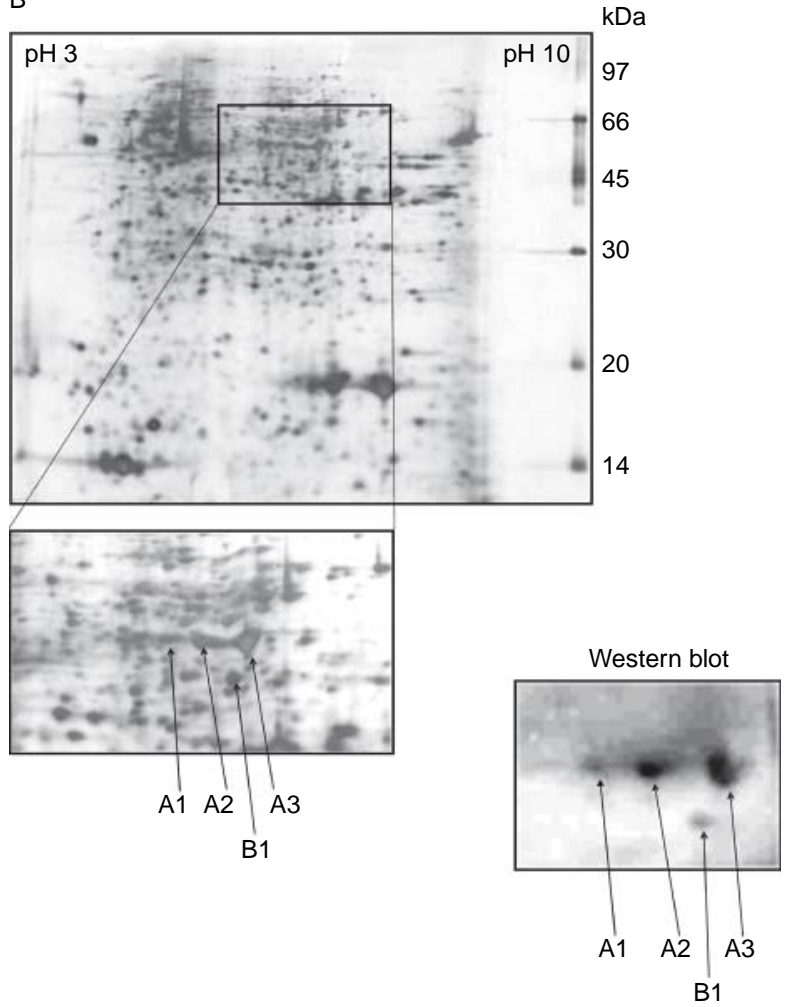

our observations were further supported by DIGE and mass spectrometric analysis. As shown in Fig. 3A, identification of annexin $\mathrm{V}$ revealed no significant differences between its expression in control and RAtreated cells, as it appeared as a white protein spot.

\section{Two-dimensional analyses revealed RA involvement in alteration of FTC-133 proteome}

To clarify previously observed effects of RA on differentiated thyroid carcinoma cell lines and possible molecular mechanisms, control and RA-treated FTC133 cells were subjected to DIGE (Fig. 3A). Automatic spot detection using DeCyder software was followed by filtering of spots in each gel. We found that out of 669 protein spots detected, RA treatment led to up-regulation of 1 and down-regulation of 8 , while 660 protein spots remained unchanged. Mass spectrometric analysis revealed that out of eight protein spots down-regulated, two of them, ENO1 and GAPDH, are related to ATP metabolism and energy production, and were previously reported to be up-regulated in thyroid oncocytomas (Baris et al. 2004). We found that both proteins exist as isoforms with differential $\mathrm{pI}$ values designated in case of ENO1 as A1, A2, and A3. The smaller $37 \mathrm{kDa}$ MBP-1 protein is labeled as B1. In fluorescent staining experiments, MBP-1 production and ENO1 spots A2 and A3 showed no significant differences between RA-treated and control samples. However, RA caused a down-regulation of the ENO1 spot corresponding to A1, which is demonstrated by its increased blue fluorescence in control sample. We could also demonstrate that RA led to decrease in GAPDH production (spot G1). It is worth to notice that besides ENO1, also GAPDH belongs to the glycolytic pathway.

Figure 3 (A) Two-dimensional fluorescence difference gel electrophoresis (DIGE) with Cy2-labeled and Cy3-labeled protein extracts derived from untreated and RA-treated FTC-133, respectively. Proteins up-regulated in RA-treated FTC-133 appear in green color, proteins with a stronger expression in the untreated control appear as blue, and equal amounts of overlaying proteins appear in white color. Experiments were done in triplicates and positions of ENO1 (A1, A2, A3, and B1) and GAPDH (G1) spots are labeled with arrows. The number of protein spots regulated upon RA treatment is presented on the diagram. Annexin $V$ appears as a white spot and indicates no induction of apoptosis upon RA treatment. (B) Two-dimensional gel electrophoresis of RA-treated FTC-133. Protein spots were visualized by silver staining. Three different protein spots corresponding to ENO1 protein with different pls (A1, A2, A3, and B1) were identified (see arrows in the enlargement) and further analyzed by mass spectrometry. Two-dimensional western blot detection verified the identity of the silver-stained protein spots $\mathrm{A} 1-\mathrm{A} 3$ and $\mathrm{B} 1$. Two-dimensional western blots were performed with $200 \mu \mathrm{g}$ total cell lysate obtained from FTC-133. Experiments were repeated at least three times. 

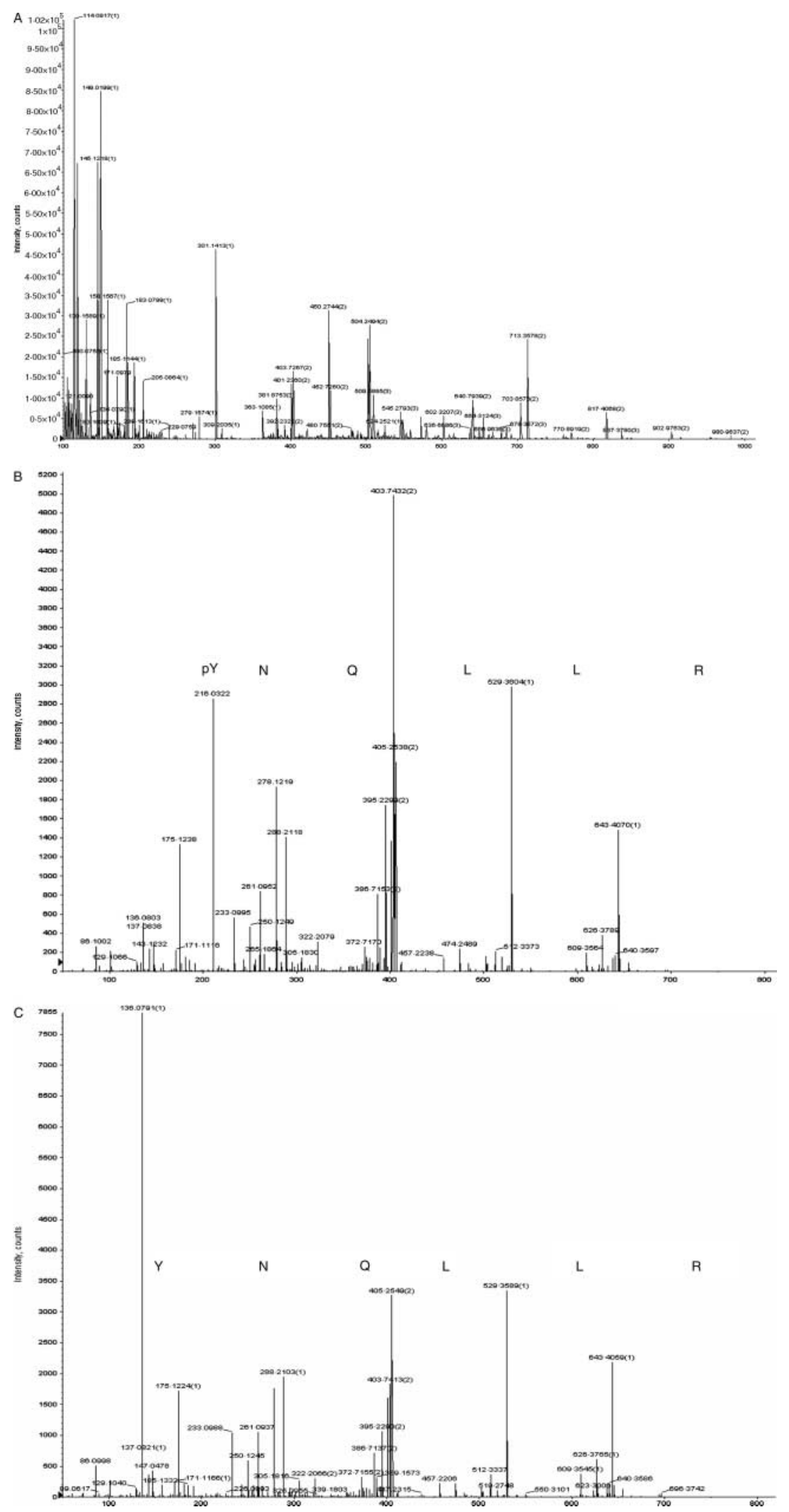


\section{RA-mediated dephosphorylation of ENO1 protein}

DIGE analysis revealed the presence of three distinct immunoreactive ENO1 proteins (A1, A2, and A3), which differed in their $\mathrm{pI}$ values. Additionally, RA treatment led to decreased expression of ENO1-A1 protein. To answer the question whether the presence of differential ENO1 isoforms and decreased expression of ENO1-A1 protein are associated with post-translational modification, control and RA-treated silver-stained gels were analyzed by mass spectrometry. Excised ENO1-related protein spots were identified using MALDI-ToF and verified by MS/MS sequencing. Employing a specific antiserum used to detect ENO1 and MBP-1, ENO1-A1-3 and MBP-1-B1 protein spots were confirmed by 2D-western blot analysis (Fig. 3B). MS/MS analysis and phosphorylation mapping demonstrated the RA-mediated dephosphorylation of ENO1A1 protein spot. ENO-A1 was first identified in the ToF MS spectrum (Fig. 4A). The ESI-MS/MS spectrum (Fig. 4B) corresponded to the ENO1-A1 peptide $\mathrm{Yp}^{407}$ NQLLR after trypsin digest and was obtained from untreated FTC-133 cells, thus, indicating a phospho-Tyr $^{407}$ in the ENO1-A1 peptide sequence. When FTC-133 were treated with RA, dephosphorylation of the ENO1-A1 tyrosine residue 407 was detected as demonstrated by the appearance of an immonium ion at $m / z$ 136.0791 typical for unphosphorylated tyrosine (Fig. 4C). Other mass differences visible by comparison of both MS/MS spectra did not match any known modifications.

\section{RA led to simultaneous down-regulation of ENO1, MYC, and MBP-1}

Previous reports demonstrated that both ENO1 and MBP-1 proteins could act as transcriptional repressors of MYC (Feo et al. 2000), and through the ability to regulate a significant number of genes, MYC itself is a key regulator of cell behavior. Additionally, many of MYC targeting pathways are deregulated in cancer cells and contribute to its enhanced expression (Vervoorts et al. 2006). In order to clarify the relationship between RA-mediated down-regulation of ENO1 gene products and reduced proliferation rates of FTC-133 and FTC238 cells, we performed western blotting. Incubation of total protein extracts obtained from both cell lines with specific ENO1 and MYC antibodies revealed that RA led to simultaneous down-regulation of all examined proteins, especially visible after $72 \mathrm{~h}$ of RA treatment (Fig. 5A and B).

Similar effects could be demonstrated after specific knock-down of ENO1. We found that employing siRNA targeting both ENO1 gene products led to decreased MYC levels accompanied by reduced proliferation rates of FTC-133 and FTC-238 cell lines (Fig. 6A and B).

\section{Discussion}

The present study identified ENO1 and MBP-1 as a novel target molecules of RA action and demonstrated a direct involvement of ENO1 in the invasiveness of human thyroid carcinoma cells. Furthermore, we demonstrated for the first time three different ENO1 (A1-A3) isoforms and showed the selective dephosphorylation of ENO1-A1 residue $\mathrm{Tyr}^{407}$ as a result of RA treatment in FTC-133 cells. RA caused a decrease in both ENO1 and MBP-1 total protein and this coincided with decreased MYC levels and reduced proliferation and motility of follicular thyroid carcinoma cell lines. ENO1 and MBP-1 are transcribed from a single transcript and share a common C-terminal $M Y C$ promotor-binding domain, but only ENO1 contains an enzymatically active N-terminal domain and, thus, displays enolase activity (Feo et al. 2000). The up-regulation of glycolytic enzymes, including ENO1 and GAPDH, appears to be a common strategy in carcinoma of diverse origin, including thyroid oncocytoma (Baris et al. 2004), suggesting a direct involvement of both enzymes in tumor growth. The impaired energy metabolism observed in FTC-133 and FTC-238 upon RA treatment likely reflected a reduction in GAPDH and $\alpha$-enolase activity and impaired glycolytic activity. A detailed comparative analysis of the effect of RA treatment on different GAPDH and ENO1 isoforms revealed a selective down-regulation of GAPDH-G1 and ENO1-A1 as determined by fluorescent DIGE, implicating both proteins as executioners for the RAinduced suppressive metabolic effects in FTC-133. We found that RA-mediated decrease in the metabolic activity and proliferation of follicular thyroid carcinoma cell lines likely involved additional mechanisms. One such cellular event elicited by RA in FTC-133 and FTC-238 was the down-regulation of the common $M Y C$ promoter-binding domain present in both ENO1 and MBP-1 (Subramanian \& Miller 2000). This

Figure 4 Mass spectrometric analyses of protein spot ENO1-A1. (A) ToF-MS spectrum of silver-stained A1-spot identified as ENO1 protein. (B) MS/MS spectrum of peptide pYNQLLR of ENO1-A1 obtained from untreated FTC-133. The characteristic immonium ion of phosphorylated tyrosine at $\mathrm{m} / \mathrm{z} 216.0322$ is present. (C) MS/MS spectrum of peptide YNQLLR in ENO1-A1 obtained from RA-stimulated FTC-133. The disappearance of the immonium ion at $m / z 216.0322$ and intensification of the immonium ion at $\mathrm{m} / z 136 \cdot 0791$ is typical for unmodified tyrosine. Analyses were done in triplicates. 
A

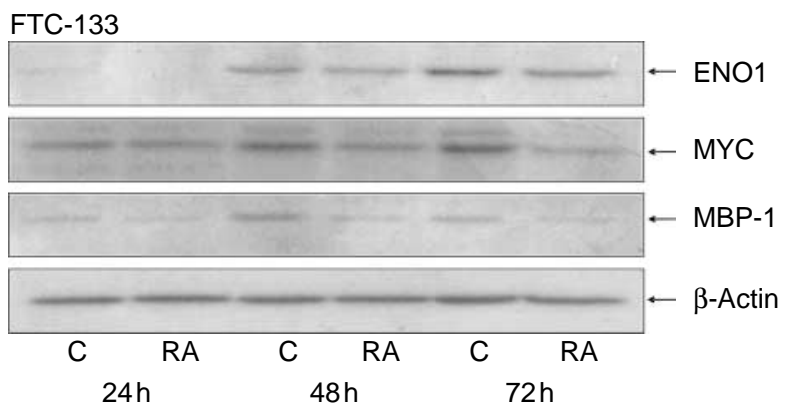

B

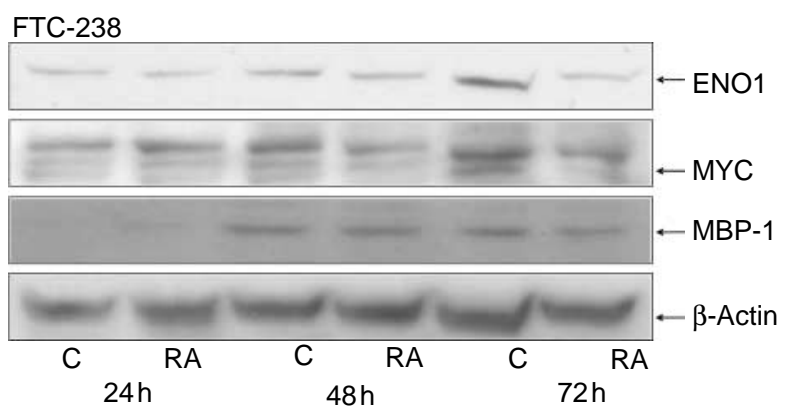

Figure 5 Western blot detection of ENO1 and MYC proteins in (A) FTC-133 and (B) FTC-238 before and after RA treatment performed with $20 \mu \mathrm{g}$ total cell lysate. ENO1 (recognizing both 48 and $37 \mathrm{kDa}$ proteins) and MYC antisera were used. $\beta$-actin served as control for equal protein loading. RA treatment resulted in the down-regulation of MYC and both ENO1 gene products.

down-regulation of ENO1 and MBP-1 coincided with a decrease of MYC suggesting an oncogene suppressive effect by which RA can impair thyroid carcinoma growth. The same effects were observed after employing specific siRNA targeting ENO1 and MBP-1. Silencing of the $M Y C$ promoter-binding domain in both proteins also led to MYC down-regulation and reduced proliferation rates of FTC-133 and FTC-238 cell lines. However, MBP-1 has been largely described to act as a repressor of the MYC, but it seems that in follicular thyroid carcinoma, the bifunctional role of enolase is diminished and ENO1 possess the enzymatic activity only. Although there is no direct evidence of the regulation of $\alpha$-enolase function by MYC, it is possible that $\alpha$-enolase gene could be affected through its two perfect CACGTG MYC-MAX binding motifs. Previous studies demonstrated that up-regulation of glycolytic enzymes as well as glycolysis occurred as a consequence of MYC overexpression. It is suggested that increased energy production was due to the interaction of MYC with two imperfect CACGTG motifs in carbohydrate response element of pyruvate kinase. The promoter of $\alpha$-enolase gene also contains CACGTC motifs and may act as MYC binding partner (Giallongo et al. 1990, Towle 1995).
A
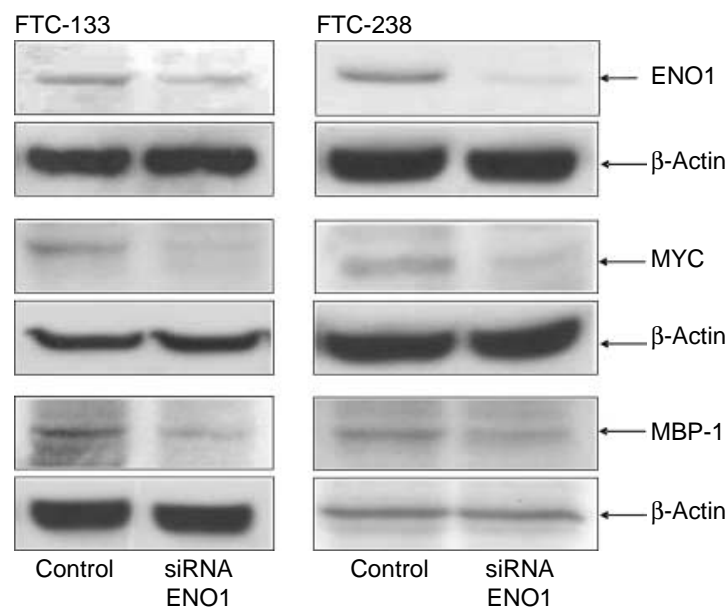

B 0.7

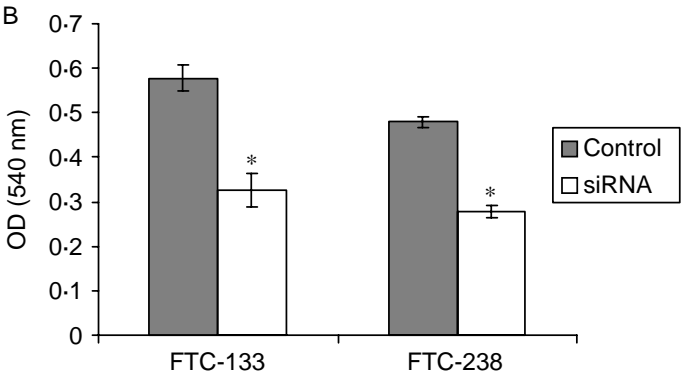

Figure 6 (A) FTC-133 and FTC-238 cells were treated with ENO1-derived siRNA (targeting common MYC binding domain) or with a scrambled, non-silencing siRNA control used at $200 \mathrm{nM}$ each. Western blot confirmed simultaneous knock-down of ENO1, MBP-1 and MYC. $\beta$-actin was used to ensure equal protein loading. (B) FTC-133 and FTC-238 treated with 200 nM ENO1 targeting siRNA displayed 44 and $42 \%$ reductions in growth respectively ( $\left.{ }^{\star} P<0 \cdot 05\right)$. Graphs summarize the results of three independent experiments.

The RA-induced down-regulation of $M Y C$ and resulting decrease in tumor cell proliferation is a common phenomenon described previously in lung cancer and myeloid cell lines (Kalemkerian et al. 1994, Akie et al. 2000, Dimberg et al. 2002, Vervoorts et al. 2006). However, information on the potential role of ENO1 and MBP-1 in these carcinoma entities is lacking.

The effect of RA on ENO1 was not restricted only to the down-regulation of the ENO1 protein, but also involved the RA-induced dephosphorylation of phosphor-Tyr ${ }^{407}$ residue in ENO1-A1 as demonstrated by mass spectrometry. Single dephosphorylation events have been shown to affect protein function and reduce cell migration and angiogenesis (Moriyama et al. 1996, Urbich et al. 2002) or increased apoptosis (Matsuoka et al. 2003). However, as demonstrated by our experiments, RA-mediated dephosphorylation of ENO1 was not associated with induction of apoptosis. RA can act post-transcriptionally to regulate the half-life 
of cell cycle proteins (Sueoka $e t$ al. 1999) and has been known to modify the activity of proteins by affecting their phosphorylation status as demonstrated for the RARG (Gianni et al. 2002). Although the functional consequences on the enzymatic or $M Y C$ promotorbinding activity of this single dephosphorylation event in ENO1-A1 remain elusive at present, our data suggested that dephosphorylated ENO1 was unable to compensate for the metabolic shortfall caused by RA.

RA therapy administrated for differentiated thyroid carcinoma is tolerated well with few side effects. We found that $1 \mu \mathrm{M}$ (300 ng/l) RA used in our study led to reduced invasiveness of two follicular carcinoma cell lines, accompanied by a decrease in ENO1 and MYC production. This could be partially explained by reduced glucose metabolism and tumor size, previously observed as a favorable response to RA therapy (Simon et al. 1998). Basal levels of natural RA (all trans) in human serum are in the range of 2-10 nM (Hong \& Itri 1994). Administration of synthetic or therapeutic levels of RA (e.g. 13 cis RA) frequently used in cancer such as leukemia (Huang et al. 1988, Castaigne et al. 1990) or dermatology therapy (Verma 1987) easily reach the low micromolar levels $(0 \cdot 5-5 \mu \mathrm{M})$ depending on time, duration, and dose of treatment. In addition, various retinoid metabolites are formed in the low to high nanomolar range. Therefore, as demonstrated before (Fex et al. 1996, Chanson et al. 2008), $1 \mu \mathrm{M}$ concentrations of RA in human serum are easy to reach in therapeutic protocols.

In summary, we identified a $48 \mathrm{kDa}$ translation product of ENO1 gene, as a novel target and executioner of the action of RA reducing the invasiveness of the human follicular thyroid carcinoma cell lines FTC-133 and FTC-238. RA-induced reduction of both the key glycolytic enzyme and proliferationpromoting MYC may serve as an additional predictive parameter of successful redifferentiation and antitumor therapy.

\section{Declaration of interest}

The authors declare that there is no conflict of interest that would prejudice the impartiality of this scientific work.

\section{Funding}

This study was partly supported by Deutsche Forschungsgemeinschaft (DFG) and Deutsche Krebshilfe.

\section{References}

Akie K, Dosaka-Akita H, Murakami A \& Kawakami Y 2000 A combination treatment of c-myc antisense DNA with all-transretinoic acid inhibits cell proliferation by downregulating c-myc expression in small cell lung cancer. Antisense E Nucleic Acid Drug Development 10 243-249.
Baris O, Savagner F, Nasser V, Loriod B, Granjeaud S, Guyetant S, Franc B, Rodien P, Rohmer V, Bertucci F et al. 2004 Transcriptional profiling reveals coordinated up-regulation of oxidative metabolism genes in thyroid oncocytic tumors. Journal of Clinical Endocrinology and Metabolism 89 994-1005.

Biesalski HK \& Nohr D 2003 Importance of vitamin-A for lung function and development. Molecular Aspects of Medicine 24 431-440.

Buletic Z, Soprano KJ \& Soprano DR 2006 Retinoid targets for the treatment of cancer. Critical Reviews in Eukaryotic Gene Expression 16 193-210.

Castaigne S, Chomienne C, Daniel MT, Ballerini P, Berger R, Fenaux P \& Degos L 1990 All-trans retinoic acid as a differentiation therapy for acute promyelocytic leukemia. I. Clinical results. Blood 76 1704-1709.

Chang YS, Wu W, Walsh G, Hong WK \& Mao L 2003 Enolase-alpha is frequently down-regulated in non-small cell lung cancer and predicts aggressive biological behavior. Clinical Cancer Research 9 3641-3644.

Chang GC, Liu KJ, Hsieh CL, Hu TS, Charoenfuprasert S, Liu HK, Luh KT, Hsu LH, Wu CW, Ting CC et al. 2006 Identification of alpha-enolase as an autoantigen in lung cancer: its overexpression is associated with clinical outcomes. Clinical Cancer Research 12 $5746-5754$.

Chanson A, Cardinault N, Rock E, Martin JF, Souteyrand P, D'Incan M \& Brachet P 2008 Decreased plasma folate concentration in young and elderly healthy subjects after a short-term supplementation with isotretinoin. Journal of the European Academy of Dermatology and Venereology 22 94-100.

Dimberg A, Bahram F, Karlberg I, Larsson LG, Nilsson K \& Oberg F 2002 Retinoic acid-induced cell cycle arrest of human myeloid cell lines is associated with sequential down-regulation of c-Myc and cyclin $\mathrm{E}$ and posttranscriptional up-regulation of p27(Kip1). Blood 99 2199-2206.

Ebert W, Muley T \& Drings P 1996 Does the assessment of serum markers in patients with lung cancer aid in the clinical decision making process? Anticancer Research 16 2161-2168.

Feo S, Arcuri D, Piddini E, Passantino R \& Giallongo A 2000 ENO1 gene product binds to the c-myc promoter and acts as a transcriptional repressor: relationship with Myc promoter-binding protein 1 (MBP-1). FEBS Letters 473 47-52.

Fex GA, Aronsson A, Andersson A, Larsson K \& Nilsson-Ehle P 1996 In vivo effects of 13-cis retinoic acid treatment on the concentration of proteins and lipids in serum. European Journal of Clinical Chemistry and Clinical Biochemistry 34 3-7.

Giallongo A, Oliva D, Calì L, Barba G, Barbieri G \& Feo S 1990 Structure of the human gene for alpha-enolase. European Journal of Biochemistry 190 567-573.

Gianni M, Kopf E, Bastien J, Oulad-Abdelghani M, Garattini E, Chambon P \& Rochette-Egly C 2002 Down-regulation of the phosphatidylinositol 3-kinase/Akt pathway is involved in retinoic acid-induced phosphorylation, degradation, and transcriptional activity of retinoic acid receptor gamma 2. Journal of Biological Chemistry 277 24859-24862.

Hansen LA, Sigman CC, Andreola F, Ross SA, Kelloff GJ \& De Luca LM 2000 Retinoids in chemoprevention and differentiation therapy. Carcinogenesis 21 1271-1279.

Hong WK \& Itri LM 1994 Retinoids and human cancer. In The Retinoids, pp 597-658. Eds MB Sporn, AB Roberts \& DS Goodman. New York, NY: Raven Press.

Huang ME, Ye YC, Chen SR, Chai JR, Lu JX, Zhoa L, Gu LJ \& Wang ZY 1988 Use of all-trans retinoic acid in the treatment of acute promyelocytic leukemia. Blood 72 567-572.

Huang LJ, Chen SX, Luo WJ, Jiang HH, Zhang PF \& Yi H 2006 Proteomic analysis of secreted proteins of non-small cell lung cancer. Ai Zheng 25 1361-1367. 
Joseph J, Cruz-Sanchez FF \& Carreras J 1996 Enolase activity and isoenzyme distribution in human brain regions and tumors. Journal of Neurochemistry 66 2484-2490.

Kaiser E, Kuzmits R, Pregant P, Burghuber O \& Worofka W 1989 Clinical biochemistry of neuron specific enolase. Clinica Chimica Acta 183 13-31.

Kalemkerian GP, Jasti RK, Celano P, Nelkin BD \& Mabry M 1994 Alltrans-retinoic acid alters myc gene expression and inhibits in vitro progression in small cell lung cancer. Cell Growth and Differentiation $\mathbf{5}$ $55-60$.

Kato K, Asai R, Shimizu A, Suzuki F \& Ariyoshi Y 1983 Immunoassay of three enolase isozymes in human serum and in blood cells. Clinica Chimica Acta 127 353-363.

Ledermann JA 1994 Serum neurone-specific enolase and other neuroendocrine markers in lung cancer. European Journal of Cancer 30 574-576.

Lengfelder E, Saussele S, Weisser A, Buchner T \& Hehlmann R 2005 Treatment concepts of acute promyelocytic leukemia. Critical Reviews in Oncology/Hematology 56 261-274.

Maden M 2000 The role of retinoic acid in embryonic and post-embryonic development. Proceedings of the Nutrition Society $\mathbf{5 9}$ $65-73$.

Matsuoka Y, Nagahara Y, Ikekita M \& Shinomiya T 2003 A novel immunosuppressive agent FTY720 induced Akt dephosphorylation in leukemia cells. British Journal of Pharmacology 138 1303-1312.

Merkulova T, Dehaupas M, Nevers MC, Creminon C, Alameddine H \& Keller A 2000 Differential modulation of alpha, beta and gamma enolase isoforms in regenerating mouse skeletal muscle. European Journal of Biochemistry 267 3735-3743.

Moriyama K, Iida K \& Yahara I 1996 Phosphorylation of Ser-3 of cofilin regulates its essential function on actin. Genes to Cells 1 73-86.

Niklinski J \& Furman M 1995 Clinical tumour markers in lung cancer. European Journal of Cancer Prevention 4 129-138.

Niles RM 2000 Recent advances in the use of vitamin A (retinoids) in the prevention and treatment of cancer. Nutrition 16 1084-1089.

Pancholi V 2001 Multifunctional alpha-enolase: its role in diseases. Cellular and Molecular Life Sciences 58 902-920.

Redlitz A, Fowler BJ, Plow EF \& Miles LA 1995 The role of an enolaserelated molecule in plasminogen binding to cells. European Journal of Biochemistry 227 407-415.

Royds JA, Parsons MA, Taylor CB \& Timperley WR 1982 Enolase isoenzyme distribution in the human brain and its tumours. Journal of Pathology 137 37-49.

Schmutzler C \& Kohrle J 2000 Retinoic acid redifferentiation therapy for thyroid cancer. Thyroid 10 393-406.

Schmutzler C, Hoang-Vu C, Rüger B \& Kohrle J 2004 Human thyroid carcinoma cell lines show different retinoic acid receptor repertoires and retinoid responses. European Journal of Endocrinology $150547-556$.
Simon D, Koehrle J, Reiners C, Boerner AR, Schmutzler C, Mainz K, Goretzki PE \& Roeher HD 1998 Redifferentiation therapy with retinoids: therapeutic option for advanced follicular and papillary thyroid carcinoma. World Journal of Surgery 22 569-574.

Simon D, Körber C, Krausch M, Segering J, Groth P, Görges R, Grünwald F, Müller-Gärtner HW, Schmutzler C, Köhrle J et al. 2002 Clinical impact of retinoids in redifferentiation therapy of advanced thyroid cancer: final results of a pilot study. European Journal of Nuclear Medicine and Molecular Imaging 29 775-782.

Subramanian A \& Miller DM 2000 Structural analysis of alpha-enolase. Mapping the functional domains involved in down-regulation of the c-myc protooncogene. Journal of Biological Chemistry $\mathbf{2 7 5}$ $5958-5965$.

Sueoka N, Lee HY, Walsh GL, Hong WK \& Kurie JM 1999 Posttranslational mechanisms contribute to the suppression of specific cyclin: CDK complexes by all-trans retinoic acid in human bronchial epithelial cells. Cancer Research 59 3838-3844.

Takashima M, Kuramitsu Y, Yokoyama Y, Iizuka N, Fujimoto M, Nishisaka T, Okita K, Oka M \& Nakamura K 2005 Overexpression of alpha enolase in hepatitis $\mathrm{C}$ virus-related hepatocellular carcinoma: association with tumor progression as determined by proteomic analysis. Proteomics 5 1686-1692.

Towle HC 1995 Metabolic regulation of gene transcription in mammals. Journal of Biological Chemistry 270 23235-23238.

Urbich C, Reissner A, Chavakis E, Dernbach E, Haendeler J, Fleming I, Zeiher AM, Kaszkin M \& Dimmeler S 2002 Dephosphorylation of endothelial nitric oxide synthase contributes to the anti-angiogenic effects of endostatin. FASEB Journal 16 706-708.

Verma AK 1987 Inhibition of both stage I and stage II mouse skin tumour promotion by retinoic acid and the dependence of inhibition of tumor promotion on the duration of retinoic acid treatment. Cancer Research 47 5097-5101.

Vervoorts J, Lüscher-Firzlaff J \& Lüscher B 2006 The ins and outs of MYC regulation by posttranslational mechanisms. Journal of Biological Chemistry 281 34725-34729.

Yoon SY, Kim JM, Oh JH, Jeon YJ, Lee DS, Kim JH, Choi JY, Ahn BM, Kim S, Yoo HS et al. 2006 Gene expression profiling of human HBV- and/or HCV-associated hepatocellular carcinoma cells using expressed sequence tags. International Journal of Oncology 29 315-327.

Zhang D, Tai LK, Wong LL, Chiu LL, Sethi SK \& Koay ES 2005 Proteomic study reveals that proteins involved in metabolic and detoxification pathways are highly expressed in HER-2/neu-positive breast cancer. Molecular and Cellular Proteomics 4 $1686-1696$.

Received in final form 15 October 2008

Accepted 5 December 2008

Made available online as an Accepted Preprint 5 December 2008 